\title{
A Chemical Mechanism for Self-ignition in a Peat Stack
}

\author{
Kari I. Hänninen \\ Department of Biological and Environmental Sciences, University of Jyvaskyla, Finland
}

Copyright $\bigcirc 2017$ by authors, all rights reserved. Authors agree that this article remains permanently open access under the terms of the Creative Commons Attribution License 4.0 International License

\begin{abstract}
Two lowest excited energy states of the ground state $\mathrm{O}_{2}\left({ }^{3} \Sigma_{\mathrm{g}}^{-}\right)$molecule, $\mathrm{O}_{2}\left({ }^{1} \Delta \mathrm{g}\right)$ and $\mathrm{O}_{2}\left({ }^{1} \Sigma_{\mathrm{g}}{ }^{+}\right)$, exist in troposphere. They are called as singlet oxygen molecules. The mechanism leading to their formation in the peat stack is indirect photolysis. Almost all chromophores which absorb UV/visible radiation are able to transfer the needed excitation energy to $\mathrm{O}_{2}\left({ }^{3} \Sigma_{\mathrm{g}}^{-}\right)$molecules. The decomposition process of organic material $(\mathrm{OM})$ in the peat stack raises its temperature and produces volatile organic compounds (VOCs), and humified OM with conjugated double bond structures. This increases the efficiency of indirect photolysis. The residence time of 14 minutes allows $\mathrm{O}_{2}\left({ }^{1} \Delta \mathrm{g}\right)$ to accumulate in sufficiently rich atmosphere inside the stack. Excess energies of $\mathrm{O}_{2}\left({ }^{1} \Delta \mathrm{g}\right)$ and $\mathrm{O}_{2}\left({ }^{1} \Sigma_{\mathrm{g}}{ }^{+}\right)$heat the system and creates from $\mathrm{VOCs} / \mathrm{OM}$ hydroxyl and peroxyl radicals which further propagate exothermic reactions. These natural heating mechanisms may locally add up enough to the overall stack temperature of 50 to $70^{\circ} \mathrm{C}$ to trigger self-ignition of VOCs. Sporadic but frequent micro-fires may generate hot spots of carbonaceous char, which achieve and maintain temperatures of 170 to $220^{\circ} \mathrm{C}$. This heat generates hot spots of smouldering fire, which may further develop to ember stage. Finally, if wind inflames, an open fire may eventually evolve in the peat stack.
\end{abstract}

Keywords Singlet Oxygen Molecules, Triggering Self-ingnition, Peat Stack

\section{Introduction}

For self-ignition to occur, organic material must be sufficiently porous to allow air to diffuse throughout the material, and it must yield a solid carbonaceous char when undergoing thermal decomposition. The combustion starts deep inside the material as a smouldering reaction, which then propagates outwards. The fire is initially deep-seated, but it may lead in suitable climatic conditions, like cold weather after rain, to flaming combustion. And then it breaks through the surface. The stacks of the material need to be large enough as well. The self-ignition process is usually rather slow, the smouldering phase may last even several months. And especially smouldering fires may be difficult to extinguish [1].

For energy production, peat is dried in large open-air stacks. When organic matter is collected in stacks, it almost always starts to compost. In well-aerated conditions, the composting process is carried out by strictly aerobic micro-organisms. Due to their activity, the organic material undergoes the humification reaction. This includes the formation of conjugated carbon - carbon double bond structures, chromophores, which give humic substances, especially humic acids, their typical dark colour.

Fires due to self-ignition cause great losses of energy peat. Various methods have been developed to prevent these fires, such as compressing peat stocks as tightly as possible and monitoring stacks from the air with thermal cameras. These methods considerably reduce the losses, but do not completely halt them.

Many other organic porous media (e.g. sawdust and woodchips) are known to self-ignite during their storage time in silos or in open windrows. On 27 August 2011 Hurricane Irene hit the city of Havelock, NC (USA). It was decided that all damaged trees and vegetation should be shredded and collected in a large heap to produce free compost for the city. The resulting biomass stockpile was about $4000 \mathrm{~m}^{3}$ in volume. The heap had been composting for five months when the fire was first detected in mid-January [2]. If the stockpile is large enough, even unprocessed feedstock may self-ignite. In Kingston, Ontario (Canada) a huge pile of wood was marked for composting. Massive mounds of wood were spread across the property, waiting to be chipped. On 2 January 2013 a smouldering fire was detected in the compost, and one pile was on fire when firefighters arrived [3].

The exact mechanism of how a physical fire develops in stacks of organic matter has so far been unknown. Laboratory tests done by Tuomisaari et al. [1] showed that the self-ignition temperature of wood chips was $170-220^{\circ} \mathrm{C}$ ). In composting of source-separated kitchen biowaste in windrows, temperatures exceeding $80^{\circ} \mathrm{C}$ have been reported [4]. When the temperature rises above $90^{\circ} \mathrm{C}$, aerobic bacteria start to die. Even their spores die in the temperature range of $104.0^{\circ} \mathrm{C}$ to $120.0^{\circ} \mathrm{C}[5]$. Biological self-heat alone, therefore, 
is not sufficient. Other mechanisms are needed, such as singlet oxygen molecules, which are at the moment also called reactive oxygen species (ROS). They were discovered in 1930's [6]. Not until in 1960's Foote found their overall importance in tropospheric environments, especially their biological importance [7].

\section{Materials and Methods}

Self-ignition of a peat stack as well as other organic materials in stockpiles has been widely studied. Importance of reactive singlet oxygen molecules is also realized in many areas of biological and environmental studies. In this meta-study is discussed the importance of singlet oxygen molecules as triggers of self-ignition in peat stack. Aim is to present a feasible chemical mechanism to explain how singlet oxygen molecules are bringing their extra energy to the local level of the system. How they increase local heating and create hydroxyl and peroxyl compounds which can propagate exothermic reactions, which further increase local heating. And how this natural self-heating, within months, will finally lead in suitable climatic conditions to open fire situation in the peat stack.

\section{Excited Oxygen Atoms and Molecules}

Atomic oxygen has a ground state $1 \mathrm{P}(\mathrm{O})$ and two excited forms $1 \mathrm{D}(\mathrm{O})$ and $1 \mathrm{~S}(\mathrm{O})$ with higher energy content. The spectroscopic term for the ground state molecular oxygen is $\mathrm{O}_{2}\left({ }^{3} \Sigma_{\mathrm{g}}\right)$ (index 3 refers to triplet state). It differs from most molecules in having an open-shell triplet ground state and four excited states with higher energy contents. The two lower excited energy states are singlet oxygen molecules $\mathrm{O}_{2}\left({ }^{1} \Delta_{\mathrm{g}}\right)$ and $\mathrm{O}_{2}\left({ }^{1} \Sigma_{\mathrm{g}}^{+}\right)$. Singlet "delta" $\mathrm{O}_{2}$ and singlet "sigma" $\mathrm{O}_{2}$ states respectively [8]. Index 1 refers to singlet state. Still higher energy state molecules are $\mathrm{O}_{2}\left({ }^{3} \Sigma^{+}\right)$and $\mathrm{O}_{2}\left({ }^{3} \Sigma_{\mathrm{u}}^{-}\right)$. Energy contents are given in Table 1.

Table 1. Energy contents of basic and excited O-atoms and those of $\mathrm{O}_{2}$-molecules [9]

\begin{tabular}{|c|c|c|c|}
\hline O-atom & Energy $/ \mathrm{kJmol}^{-1}$ & $\mathrm{O}_{2}$ molecule & Energy kJmol \\
\hline $1 \mathrm{P}$ & 249.2 & ${ }^{3} \Sigma^{-} \mathrm{g}$ & 249.2 \\
\hline $1 \mathrm{D}$ & 438.9 & ${ }^{1} \Delta \mathrm{g}$ & $249.2+92.6$ \\
\hline $1 \mathrm{~S}$ & 653 & ${ }^{1} \Sigma^{+} \mathrm{g}$ & $249.2+154$ \\
\hline & & ${ }^{3} \Sigma^{+} \mathrm{u}$ & $249.2+418.6$ \\
\hline & & ${ }^{3} \Sigma^{-} \mathrm{u}$ & $249.2+586.1$ \\
\hline
\end{tabular}

Chemically, all excited oxygen atoms and molecules react similarly but more vigorous than normal ground state oxygen atom or molecule. That is why they are important active but often "invisible" intermediates involved in chemical reactions in atmosphere as well as in biochemical reactions. All excited $\mathrm{O}$ atoms and $\mathrm{O}_{2}$ molecules exist and function in the upper atmosphere (mesosphere and thermosphere). There they form via absorption of UV-light (Table 2). The higher excited energy states may occur in troposphere only momentarily, via high energy bursts like during lightning or when engine is running etc.

Table 2. Threshold values of wave lengths ( $\mathrm{nm})$ below which reactions in ozone photolysis are possible [9]

\begin{tabular}{|c|c|c|c|c|c|}
\hline \multirow{2}{*}{$\begin{array}{c}\text { Basic and } \\
\text { excited } \\
\text { oxygen } \\
\text { atoms }\end{array}$} & \multicolumn{5}{|c|}{ Basic and excited oxygen molecules } \\
\cline { 2 - 6 } & ${ }^{3} \Sigma^{-} \mathrm{g}$ & ${ }^{1} \Delta \mathrm{g}$ & ${ }^{1} \Sigma^{+} \mathrm{g}$ & ${ }^{3} \Sigma^{+} \mathrm{u}$ & ${ }^{3} \Sigma^{-} \mathrm{u}$ \\
\hline 3P & 1180 & 612 & 463 & 230 & 173 \\
\hline $1 \mathrm{D}$ & 411 & 310 & 267 & 168 & 136 \\
\hline 1S & 237 & 199 & 181 & 129 & 109 \\
\hline
\end{tabular}

In addition to ground state $\mathrm{O}_{2}$ molecules only the two lowest energy states of singlet oxygen molecules $\mathrm{O}_{2}\left({ }^{1} \Delta_{\mathrm{g}}\right)$ and $\mathrm{O}_{2}\left({ }^{1} \Sigma_{\mathrm{g}}^{+}\right)$are permanently present in troposphere. To fully appreciate the reactivity of these molecules, it is necessary to understand their physical and chemical nature via the quantum theory of atomic and molecular structures.

\subsection{Orbital Configurations of Excited Oxygen Molecules}

The occupation of orbitals in oxygen atom having 8 electrons is $1 \mathrm{~s}^{2} 2 \mathrm{~s}^{2} 2 \mathrm{px}^{2} 2 \mathrm{p}_{\mathrm{y}}{ }^{1} 2 \mathrm{p}_{\mathrm{z}}{ }^{1}$. The occupation of molecular orbitals (MOs) in the ground state of $\mathrm{O}_{2}$ molecules, having 16 electrons, is $\left(1 \sigma_{\mathrm{g}}\right)^{2}\left(1 \sigma_{\mathrm{u}}\right)^{2}\left(2 \sigma_{\mathrm{g}}\right)^{2}\left(2 \sigma_{\mathrm{u}}\right)^{2}\left(3 \square_{\mathrm{g}}\right)^{2}\left(1 \pi_{\mathrm{u}}\right)^{4}\left(1 \pi_{\mathrm{g}}\right)^{2}$. Instead of $\mathrm{s}$ and $\mathrm{p}$ is now used Greek letters $\sigma$ and $\pi$ respectively in marking of orbitals $[10,11]$.

Paramagnetism of molecular oxygen is accounted by the unpaired electrons in two different molecular $\pi_{\mathrm{g}}$-orbitals (MOs). The electron occupancies of the outer MOs $\left(1 \pi_{\mathrm{g}}\right)^{2}$ of the ground state and of the two excited states are depicted in Figure 1. In the ground state two electrons having the same orientation (spin) occupy two different $\pi_{\mathrm{g}}$ MOs. In the lowest excited state $\mathrm{O}_{2}\left({ }^{1} \Delta_{\mathrm{g}}\right)$, two electrons having opposite orientation occupy the same $\pi_{\mathrm{g}} \mathrm{MO}$. In the higher energy excited state $\mathrm{O}_{2}\left({ }^{1} \Sigma_{\mathrm{g}}^{+}\right)$, two electrons having opposite orientation occupy two different $\pi_{\mathrm{g}}$ MOs. Ground state $\mathrm{O}_{2}$ and singlet sigma $\mathrm{O}_{2}$ molecules, like iron, have unpaired electrons in its outer shell, which create the tiny electromagnetic currents required for it to be attracted to a magnetic field. Singlet delta $\mathrm{O}_{2}$ molecule has no unpaired electrons and therefore no net electron spin. The ${ }^{1} \Delta_{\mathrm{g}}$ has paired electrons, however it is paramagnetic as shown by the observation of an electron paramagnetic resonance (EPR) spectrum [12]. 


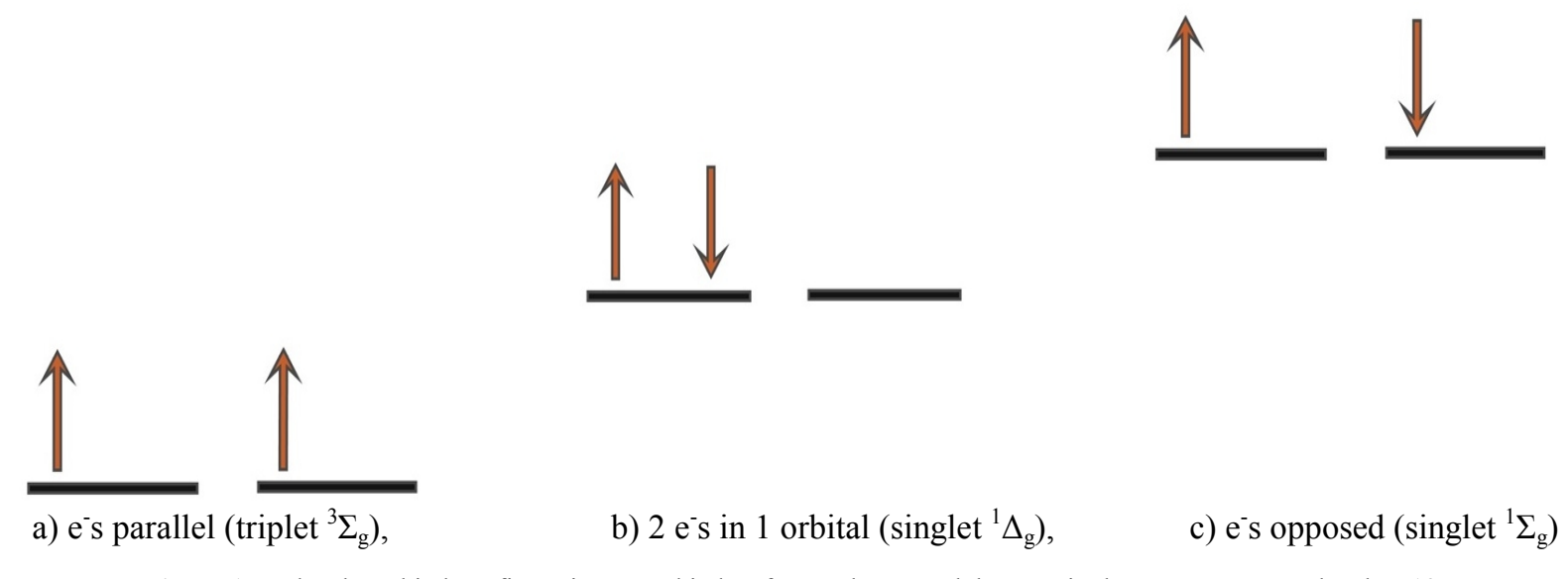

Figure 1. Molecular orbital configurations, $\pi$-orbitals, of ground state and the two singlet state oxygen molecules [13]

One mole of $\mathrm{O}_{2}\left({ }^{1} \Delta_{\mathrm{g}}\right)$ has $0.98 \mathrm{eV}\left(92.6 \mathrm{kJmol}^{-1}\right)$ more energy than one mole of ground state (triplet state) oxygen molecules. So transition from: ${ }^{1} \Delta_{\mathrm{g}}$ to ${ }^{3} \Sigma_{\mathrm{g}}^{-}$yields energy 92.6 $\mathrm{kJmol}^{-1}$. One mole of the upper energy singlet oxygen molecules $\mathrm{O}_{2}\left({ }^{1} \Sigma_{\mathrm{g}}{ }^{+}\right)$has $1.63 \mathrm{eV}\left(154 \mathrm{kJmol}^{-1}\right)$ more energy than one mole of the ground state $\mathrm{O}_{2}$ The radiative decay lifetime of $\mathrm{O}_{2}\left({ }^{1} \Delta_{\mathrm{g}}\right)$ is 45 minutes at very low gas pressures. However, at normal pressure of $101.325 \mathrm{kPa}(760 \mathrm{mmHg})$, collisions with other molecules shorten its lifetime to about 14 minutes. The decay lifetime of $\mathrm{O}_{2}\left({ }^{1} \Sigma_{\mathrm{g}}{ }^{+}\right)$in condensed media is 7 seconds [10]. If it is then converted to $\mathrm{O}_{2}\left({ }^{1} \Delta_{\mathrm{g}}\right)$ the transition yields energy $154 \mathrm{kJmol}^{-!}-92.6 \mathrm{kJmol}^{-1}=61.4$ $\mathrm{kJmol}^{-1}[9,14]$.

Minor amounts of the singlet $\mathrm{O}_{2}$-molecules in troposphere are formed via ozone dissociation or when ozone or ${ }^{1} \mathrm{D}(\mathrm{O})$ reacts with ground state $\mathrm{O}_{2}$-molecule. Basic formation method of singlet oxygen molecules in tropospheric environments is indirect photolysis [15].

\subsection{Generation of Singlet Oxygen Molecules via Indirect Photolysis}

As stated, indirect photolysis is the most important mechanism leading to the formation of a singlet oxygen molecule in troposphere, and so for example in a peat stack. Almost all chromophores, which absorb UV or visible radiation are able to transfer the needed energy to ground state oxygen molecule, and excite it to the singlet delta and sigma states $\mathrm{O}_{2}$ [15].

In photosynthesis, singlet oxygen molecules can be produced from the light-harvesting chlorophyll molecules. One of the roles of carotenoids in photosynthetic systems is to prevent damage caused by any singlet oxygen molecules that is produced by either removing excess light energy from chlorophyll molecules, or quenching the singlet oxygen molecules directly [16]

Reactive oxygen species (ROS) (or singlet oxygen molecule) are known to form from dissolved organic matter (DOM) photochemistry. Recently, it has been determined that humic-like substances and unknown organic chromophores are significant contributors to sunlight absorption in snowpack [17]. Fede and Grannas [17] described the singlet oxygen molecules with symbol ${ }^{1} \mathrm{O}_{2}$. It may include both $\mathrm{O}_{2}\left({ }^{1} \Delta_{\mathrm{g}}\right)$ and $\mathrm{O}_{2}\left({ }^{1} \Sigma_{\mathrm{g}}{ }^{+}\right)$states. The authors observed that the production of singlet oxygen molecules is enhanced up to nearly 1000 times more in frozen DOM samples than in liquid samples. The temperature range of 228-262 K of frozen samples has a significant increasing effect on the production steady-state (delta) ${ }^{1} \mathrm{O}_{2}$, with colder samples producing more of ${ }^{1} \mathrm{O}_{2}$. The large enhancement in ${ }^{1} \mathrm{O}_{2}$ in frozen samples suggests that it may play a significant role in the photochemical processes that occur in snow and ice, and DOM could be a significant, but to date poorly understood, oxidant source in snow and ice [17]. A very interesting deduction made from this study is that even the troposphere of boreal and subarctic zones is receiving singlet oxygen molecules through the year!

\subsection{Activation Energy, Self-ignition of Linseed Oil}

Activation energy is the minimum energy required to start a chemical reaction (Figure 2). The activation energy of a reaction is usually denoted by $E_{a}$ and given in units of kilojoules per mole $\left(\mathrm{kJmol}^{-1}\right)$ or kilocalories per mole $\left(\mathrm{kcalmol}^{-1}\right)$. The reaction rate decreases with a decrease in temperature. Catalysts can lower the activation energy and increase the reaction rate without being consumed in the reaction. $\Delta \mathrm{G}^{\mathrm{o}}$ describes Gibbs energy and denotes the energy on the transition state. 


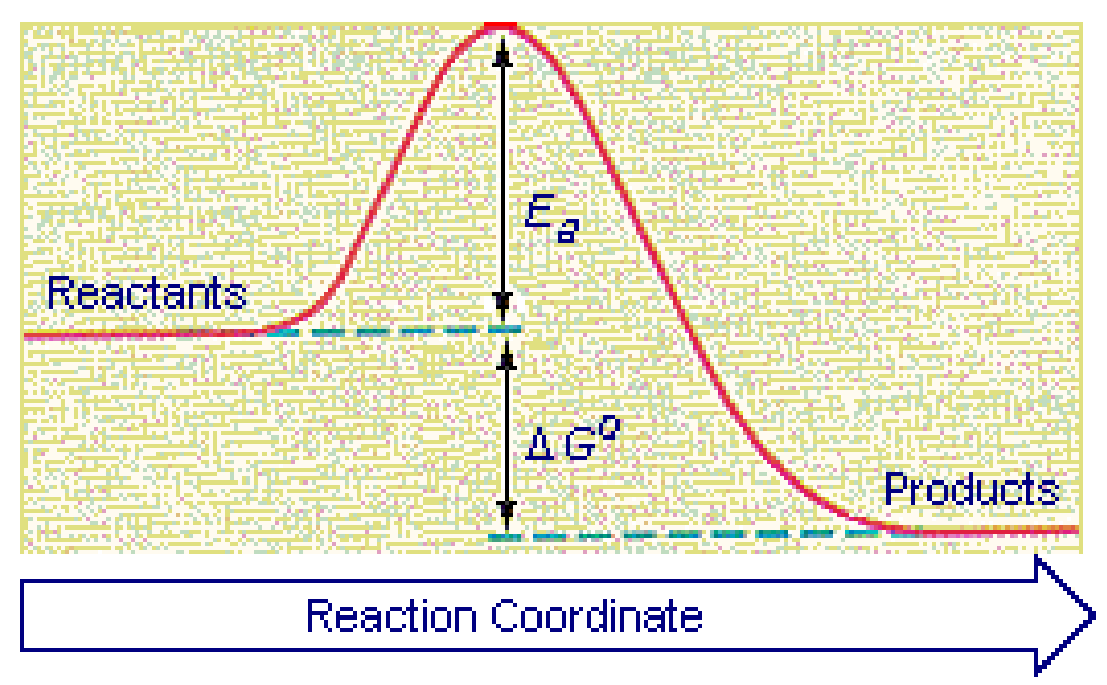

Figure 2. Activation energy

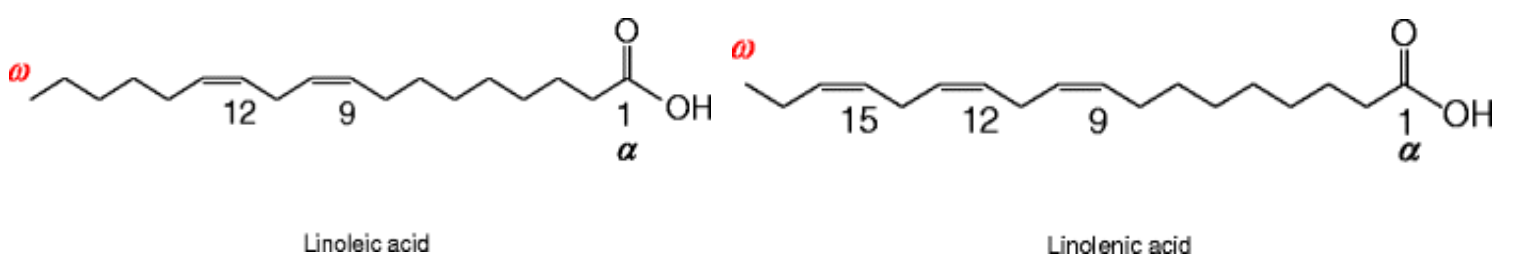

Figure 3. Conjugated double bond structures of linoleic and linolenic acids

Linseed oil is natural product from the seed of flax plant. Due to its good drying properties it has been widely used in industrial products such as paint and linoleum floor covering. It contains a high percentage of esters of polyunsaturated fatty acids from which most important are linoleic and linolenic acid (Figure 3). Conjugated carbon- carbon double bonds are acting as chromophores for the formation of singlet oxygen molecules via indirect photolysis.

Linseed oil is known of its readiness for self-ignition at room temperature or even below. One worker while using a linseed oil based decking stain, tossed the soaked rags into a bucket along with other trash (paper towels, a rag previously soaked in mineral spirits, etc.) The bucket caught fire after the worker left the job site. Fortunately the bucket was in the driveway and away from the house - a good precaution!

According to Juita et al. [18] initiation of radical chains by singlet oxygen $\left({ }^{1} \Delta_{\mathrm{g}}\right)$, and their propagation underpin the mechanism of oxidation of linseed oil, leading to the self-heating and formation of volatile organic species and higher molecular weight compounds.

In other research they explain the readiness of linseed oil to self-ignite by the fact that linseed oil contains cobalt, which function in the oxidation reactions as catalyst. They obtained the enthalpy of self-ignition reaction (activation energy) of linseed oil to be $68 \mathrm{kJmol}^{-1}$ by subtracting the total enthalpy of products with the total enthalpy of reactants [19]. From Table 3 one can see that other estimates of the needed activation energy for the self-ignition of linseed oil range between 17 to $88 \mathrm{kJmol}^{-1}$ depending on linseed oil concentrations.

Considering that singlet delta $\mathrm{O}_{2}$ molecule has 92.6 $\mathrm{kJmol}^{-1}$ and singlet delta $\mathrm{O}_{2}$ has $154 \mathrm{kJmol}^{-1}$ of excess energy as compared to ground state $\mathrm{O}_{2}$ molecule, one can deduce that singlet oxygen molecules are able to transfer the needed activation energy for the self-ignition of linseed oil at room temperature or even below. 
Table 3. Activation energies of some linseed oil products

\begin{tabular}{|c|c|c|c|c|c|c|}
\hline Linseed oil mass percentage ( $\%)$ & $\mathrm{E}$ & A $\Delta \mathrm{H}_{\mathrm{c}}$ & $\rho$ & $\mathrm{k}$ & $\mathrm{c}$ & Ref \\
\hline & $\mathrm{kJ} \quad \mathrm{imol}$ & W $\quad k g$ & $\mathrm{~kg} \quad-i \operatorname{m}$ & $\mathrm{W}(\mathrm{m} \cdot \mathrm{K})^{-1}$ & $\mathrm{~J}(\mathrm{~kg} \cdot \mathrm{K})^{-1}$ & \\
\hline 16.7 & 88 & $\stackrel{13}{\times 10}$ & 309 & 0.046 & 1400 & {$[20]$ and [21] } \\
\hline 33.3 & 42.37 & 2.60 & 96 & 0.089 & 1465 & {$[22]$} \\
\hline 50 & 27.4 & $2.27 \quad 8 \times 1$ & 128 & 0.104 & 1548 & {$[22]$} \\
\hline 75 & 16.97 & $5.30 \quad 6 \times 1$ & 329 & 0.125 & 1672 & [22] \\
\hline
\end{tabular}

\subsection{Mechanism of Peroxide Formation in Linseed Oil and in Peat Stack Material}

According to Dlugorski et al. [19] the organic, polyunsaturated material of linseed oil $(\mathrm{RH})$ reacts with (singlet delta and singlet sigma) oxygen molecule to form organic peroxides. They then decompose into alkoxyl and hydroxyl radicals. Alkoxyl radicals can cross link with each other to form polymerization product and also can undergo scission reaction to form products such as aldehydes, acids and lower hydrocarbons.
1. $\mathrm{RH}+\mathrm{O}_{2}\left({ }^{1} \Delta_{\mathrm{g}}\right) \rightarrow \mathrm{ROOH}$
2. $\mathrm{ROOH} \rightarrow \mathrm{RO}^{\circ}+\mathrm{HO}^{\circ}$
3. $\mathrm{RH}+\mathrm{HO}^{\circ} \rightarrow \mathrm{R}^{\prime}+\mathrm{H}_{2} \mathrm{O}$
4. $\mathrm{O}_{2}\left({ }^{1} \Delta_{\mathrm{g}}\right)+\mathrm{R}^{\cdot} \rightarrow \mathrm{ROO}$
5. $\mathrm{RH}+\mathrm{ROO}^{\circ} \rightarrow \mathrm{ROOH}+\mathrm{R}^{\circ}$
6. $\mathrm{ROOH} \rightarrow \mathrm{ROO}^{\circ}+\mathrm{H}^{\circ}$
7. $\mathrm{RO}^{\circ}+\mathrm{RO}^{\circ} \rightarrow \mathrm{ROOR}$

According to Dlugorski et al. [18] the decomposition products of peroxide compounds include alkoxyl, peroxyl and hydroxyl radicals. The $\mathrm{OH}$ radical is the primary species responsible for the consumption of organic compounds under atmospheric conditions. It is a very active radical, which can abstract hydrogen from the parent oils and hence initiate oxidation chain reactions. The abstraction reactions consuming hydroxyl radical are generally very exothermic, typically $75-100 \mathrm{~kJ} \mathrm{~mol}^{-1}$ for alkanes, with low activation energies, hence these reactions are relatively fast at room temperature and even below. This mechanism, combined with the excess energy of singlet oxygen molecules, may be responsible for the relatively rapid, low-temperature self-heating of linseed oil. Here needs, in addition, to notice the observation of Frank and Blackham [23]. They determined the effects on many organic compounds on the spontaneous ignition temperature of $\mathrm{n}$-dodecane. They observed that $t$ - butylperoxide lowered the S.I.T. (self-ignition temperature) of n-dodecane.

According to Dlugorski et al. [19] in linseed oil carbon dioxide is the dominant gaseous species produced, with other products, including carbon monoxide, ethane, ethylene, acetaldehyde, propionaldehyde, acrolein and formic acid, formed at lower yields. Oxidation can proceed in a controlled manner via 'slow reactions' or through a rapid increase in rate, which leads to explosion or ignition. There are two ways of causing an increased rate; through the exponential increase in the number of radicals or chain branching reactions and the effect of a rapid temperature rise as a result of exothermic reactions.

\subsection{Importance of Excited Oxygen Molecules to Life of Biological Organisms}

The formation enthalpy of one mole of the ground state $\mathrm{O}_{2}$ molecule is $249.2 \mathrm{kJmol}^{-1}$, while that of $\mathrm{O}_{2}\left({ }^{1} \Delta_{\mathrm{g}}\right)$ is 341.8 $\mathrm{kJmol}^{-1}$ and that of $\mathrm{O}_{2}\left({ }^{1} \Sigma \mathrm{g}^{+}\right)$is $403.2 \mathrm{kJmol}^{-1}$. With the aid of their excess energies, the singlet oxygen molecules (mainly singlet delta $\mathrm{O}_{2}$ ) oxidize $\mathrm{F}^{2+}$ irons (ferrous iron) to $\mathrm{Fe}^{3+}$ irons (ferric iron) in human blood circulation. As oxygen transport is a vital life supporting function, our body is recovering by enzymatic reduction more than $95 \%$ of ferric iron back to ferrous iron [24]. These processes generate large amount of oxidants. For this reason humans at least should include some antioxidants in their daily diet. Men and women differ from each other by the metabolism of iron. Women have a menstruation period of some 40 years during which they on monthly bases are losing blood. The old people emphasize the importance of cupping by saying that "bad" blood needs to be removed. Maybe, if men were donating blood on regular basis during a 40 -years period, they would be able to live as long as women!

Mole rats are subterranean animals. They live most of their life under the earth [25]. They may reach the age of 29 years. Many times more than the life span of our ordinary mouse. In subterranean environment there is no sunshine, no indirect photolysis, and subsequently no in situ formation of singlet oxygen molecules. Diffusion of outside air through the soil takes much time, during which singlet oxygen concentrations are radically reduced! Absence of singlet oxygen molecules may be one reason for the long life of mole rats.

In trees each part, such as leaves/needles, stems and roots, perform their own respiration. Except leaves and needles during daytime, respiration takes place also at much slower rate as compared to animals. Also, there is very little transportation of respiratory gases from one part of the plant to another. In the plants having hard and woody stems and 
mature roots the exchange of gases takes place through lenticels. Respiration of plants also takes place through roots. In soil oxygenated air is present in spaces between soil particles. This oxygen is absorbed into the roots by root hairs. In leaves the exchange of respiratory gases takes place through very small pores called stomata. [26]. Dissolving of oxygen into soil takes so much time, which roots most likely get their oxygen free from singlet oxygen molecules. Stem cells get oxygen through the lenticles probably so slowly that much of its singlet oxygen molecules will relax to ground state, before reaching the actual cell. In leaves and needles respiration is faster than in other parts of a tree. Singlet oxygen molecules are formed during photosynthesis in leaves and needles, so they are more predisposed to the harmful effects of singlet oxygen molecules than other parts of plants. This may be one reason why tree leaves and needles have a relatively short life span, but a tree as wholeness can live even two thousand years!

\section{Triggering Self-ignition in a Peat Stack}

Self-ignition of linseed oil is taken place in a few hours, and even at room temperature or below. In peat stack the self-heating process needs more time, weeks or even several months in a temperature frame of 50 to $70^{\circ} \mathrm{C}$. However, it is relevant to suppose that in peat stack the self-ignition is taken place similarly than in the case of linseed oil.

The indirect photolysis is taken place in locations where the stack receives solar radiation, mostly at the top and on the edges of the stack. From these locations, singlet oxygen molecules then move towards the inside of the stack. The decomposition process of organic material $\mathrm{OM}$ ) in the stack produces chromophores, i.e. compounds structures of which have conjugated carbon - carbon double bonds, volatile organic compounds (VOCs) and the exothermic microbiological decomposition process keeps the temperature at an elevated level. With increasing number of chromophores, the formation of singlet oxygen molecules will increase. This increases the formation of hydroxyl and peroxyl radicals from $\mathrm{OM}$ and VOCs. These radicals undergo then more exothermic reactions. Heat produced by these reactions will locally add up the overall temperature frame of 50 to $70^{\circ} \mathrm{C}$. Increase may be enough to develop small sporadic physical micro-fires into certain parts of the stack. Those micro-fires may be so frequent that they generate carbonaceous char in amounts which are able to achieve and maintain the needed temperature of 170 to $220^{\circ} \mathrm{C}$. Hot spots of carbonaceous char will develop. Within weeks or even months they increase in volume and create hot spots of smouldering fire. The surface oxidation of the char intensifies. This oxidation produces so much excess heat that thermal degradation will advance to the neighbouring layers on that particular spot of combustible material. Most actively heated spot(s) will develop to a glowing ember stage(s). If the wind is inflaming, in the ember stage(s) will eventually develop open into fire(s).

Cold weather and rain are known to increase the possibility of peat stack/windrows of OM to self-ignite. During those climatic conditions, the formation of singlet oxygen molecules via indirect photolysis in the stack increases. Their radiative decay life-time (residence time) may be longer in cold weather as well. Then the number of $\mathrm{O}_{2}\left({ }^{1} \Delta_{\mathrm{g}}\right)$ molecule may be high also inside the stack. Possibility that two $\mathrm{O}_{2}\left({ }^{1} \Delta_{\mathrm{g}}\right)$ molecules would collide inside the stack increases:

$$
\text { 8. } \begin{aligned}
\mathrm{O}_{2}\left({ }^{1} \Delta_{\mathrm{g}}\right) & +\mathrm{O}_{2}\left({ }^{1} \Delta_{\mathrm{g}}\right) \rightarrow \mathrm{O}_{2}\left({ }^{1} \Sigma_{\mathrm{g}}{ }^{+}\right)+\mathrm{O}_{2}\left({ }^{3} \Sigma_{\mathrm{g}}{ }^{-}\right) \\
& +30.2 \mathrm{kJmol}^{-1} \text { of excess energy }
\end{aligned}
$$

The resulting singlet sigma $\mathrm{O}_{2}$ molecules have the residence time of 7 seconds only. When they are formed via indirect photolysis in the sunny sides of the peat stack, they will relax to ground state $\mathrm{O}_{2}$ molecule before they get inside the stack. But if and when they are formed inside the stack in collision of two singlet delta $\mathrm{O}_{2}$ molecules, 7 seconds is enough time for them to react with the OM of humified peat or oxidize VOCs. And do it with the energy of $154 \mathrm{kJmol}^{-1}$. This enhances considerable the formation of reactive peroxyl radicals in reactions that are described earlier in chapter 3.4 (reactions 1 to 7). The collision of two moles of singlet delta $\mathrm{O}_{2}$ molecules gives also excess energy of $30.2 \mathrm{kJmol}^{-1}$ for local heating (reaction 8 ). This chain of events is enhanced during cold weather conditions, and it may explain why the stacks in the cities of Havelock and Kingston developed open fires in January. Also we may deduce that the singlet oxygen molecules may have importance in generation of forest fires, natural cause of which are at moment considered to be ignition by flash of lightning.

\section{Conclusions}

Two energetic singlet state oxygen molecules, $\mathrm{O}_{2}\left({ }^{1} \Delta_{\mathrm{g}}\right)$ (singlet delta $\mathrm{O}_{2}$ ) and $\mathrm{O}_{2}\left({ }^{1} \Sigma_{\mathrm{g}}{ }^{+}\right.$) (singlet sigma $\mathrm{O}_{2}$ ), are formed by indirect photolysis in the peat stacks. They act as triggers of self-ignition in the critical transformation stage where, under overall 50 to $70^{\circ} \mathrm{C}$ temperature frame produced microbiologically when OM of a peat stack is composting. Otherwise for self-ignition of organic matter is in normal conditions required a temperature range of $170-220^{\circ} \mathrm{C}$.

The triggering effect of singlet state oxygen molecules is their ability to react with the peat OM, and especially with the VOCs generated during composting. Reactions lead to the formation of hydroxyl and peroxyl radicals that which are able to react exothermic as well. Local temperature may boost so much that self-ignition threshold of certain most inflammable VOCs will be reached. Sporadic but frequent micro-fires are formed in certain spots of peat stack. They generate carbonaceous char so much that it is able to achieve and maintain the needed self-ignition temperature of 170 to 
$220^{\circ} \mathrm{C}$. Hot spots of carbonaceous char will develop. Within weeks or even months they increase in volume and create hot spots of smouldering fire. This intensifies the surface oxidation of the char. This oxidation produces so much excess heat that thermal degradation will advance to the neighbouring layers on that particular spot of combustible material. Most actively heated spot(s) will develop to a glowing ember stage(s). If the wind is inflaming, the ember stage(s) will eventually develop into open fire(s). This happens usually during cold weather conditions, after rain or in cold seasons.

It has been shown that in cold conditions, the formation of singlet oxygen molecules increases. Collision of two moles of singlet delta $\mathrm{O}_{2}$ inside the stack creates one mole of ground state $\mathrm{O}_{2}$ molecules and one mole of energetic singlet sigma $\mathrm{O}_{2}$ molecules which enhances all radical forming reactions. Supposed that number of collisions of singlet delta $\mathrm{O}_{2}$ molecules is large enough, additional energy provided by exothermic reactions will locally boost the temperature of the system so much that all what is needed is windy weather, and an open fire situation in the peat stack is inevitable.

\section{REFERENCES}

[1] M. Tuomisaari, D. Baroudi and R. Latva. Extinguishing smouldering fires in silos. BRANDFORSK project 745-961 (Technical Research Centre of Finland, VTT Publications 339, 1998). Retrieved from http://www.vtt.fi/inf/pdf/publications/1 998/P339.pdf

[2] G. Rein. Smouldering fire of large compost heap in Havelock, 2012. Retrieved from http://guillermo-rein.blogspot.fi/2012/0 1/smouldering-fire-of-large-biomass-heap.html

[3] M. Lea. Fire at wood composter. The Kingston Whig-Standard, 2013, January 2. Retrieved from http://www.thewhig.com/201 3/01/02/fire-at-wood-composter

[4] N. Koivula, K. Hänninen, and O. Tolvanen. Windrow composting of source separated kitchen biowastes in Finland. Water Management and Research, Vol. 18, 160-173, 2000. DOI: $10.1177 / 0734242 X 0001800208$

[5] D. R. Theophilus, and B. W. Hammer. Influence of growth temperature on the thermal resistance of some bacteria from evaporated milk. Research Bulletin 244, 1938. Iowa State College of Agriculture and Mechanics Arts.

[6] A. U. Khan. The discovery of the chemical evolution of singlet oxygen. Some current chemical, photochemical, and biological applications, Quantum Chemistry Vol. 39 No.3 251 - 267, 1991. DOI: 10.1002 /qua.560390305

[7] A. Greer. Christopher Foote's Discovery of the Role of Singlet Oxygen $[1 \mathrm{O} 2(1 \Delta \mathrm{g})]$ in Photosensitized Oxidation Reactions, Accounts of Chemical Research, Vol. 39, No 11, 797-804, 2006, DOI: 10.1021/ar050191g

[8] D. Weldon, T. D. Poulsen, K. V. Mikkelsen and P. R. Ogilby. Invited Review Singlet Sigma: The "Other" Singlet Oxygen in Solution Photochemistry and Photobiology. Vol. 70 No 4, 369-379, 1999.
[9] B. J. Finnlayson-Pitts \& J. N. Pitts, Jr. Chemistry of the upper and lower atmosphere. New York 2000, NY: Academic Press.

[10] L. G. Grossweiner. Singlet Oxygen: Generation and Properties. Retrieved from http://www.photobiology.com/educational/len 2/singox.html

[11] J. S. Morrill, M. L. Ginter, B. R. Lewis and S. T. Gibson. Review of the Electronic Structure of Molecular Oxygen. Retrieved from http://physics.nist.gov/Icamdata/PDF/3DataPr oduction/33Molecules/morrill.pdf

[12] A. M. Falick, B. H. Mahan, and R. J. Myers. Paramagnetic Resonance Spectrum of the ${ }^{1} \Delta_{g}$ Oxygen Molecule. The Journal of Physical Chemistry Vol. 42 No. 5, 1837-1838, 2004. http://dx.doi.org/10.1063/1.1696199

[13] http://www.idconline.com/technical_references/pdfs/chemical _engineering/Dioxygen_O2.pdf

[14] S. P. McGlynn, T. Azumi, and M. Kinoshita. The molecular spectroscopy of the triplet state, p. 101, 1969, New Jersey: Prentice Hall.

[15] R. P. Schwarzenbach, P. M. Gschwend, \& D. M. Imboden.. Environmental organic chemistry, p. 472, 1993. New York: John Wiley and Sons.

[16]F. Ramel, S. Birtic, C. Triantaphylides, J. L. Ravanat and M. Havaux. Chemical quenching of singlet oxygen by carotenoids in plants. Plant Physiology Vol. 158 No 31267 -78, 2012. Doi: 10.1104/pp.111.182394.

[17] A. Fede and A. M. Grannas. Photochemical production of singlet oxygen from dissolved organic matter in ice, Environ. Sci. Technol., Vol. 49, no. 21, 12808-12815, 2015. DOI: 10.1021 /acs.est. 5 b03600

[18] Juita, B. Z. Dlugogorski, E. M. Kennedy and J. C. Mackie. Low temperature oxidation of linseed oil: a review, Fire Science Reviews December 2012, 1:3. DOI: 10.1186/2193-0414-1-3

[19] B. Z. Dlugogorski, E. M. Kennedy and J. C. Mackie. Linseed Oil and its Tendency to Self-Heat. Fire Safety Science Vol. 10, 389-400, 2011. 10.3801/IAFSS.FSS.10-389.

[20]D. Gross and A. F. Robertson. Self-Ignition Temperatures of Materials From Kinetic Reaction Data, Journal of Research of the National Bureau of Standards Vol. 61, No.5, Research Paper 2909, November 1958. Google Scholar

[21] J. T. Worden. Spontaneous Ignition of Linseed Oil Soaked Cotton using the Oven Basket and Crossing Point Methods. University of Maryland, Maryland, 2011.Google Scholar

[22] V. Babrauskas. Ignition Handbook. Fire Science Publishers, 2003. Google Scholar

[23] C. E. Frank and A.U. Blackham. Spontaneous ignition of Organic Compounds, Industrial \& Engineering Chemistry Vol. 44, $862-7,1952$.

[24] S.R. Williams. Methemoglobin. Retrieved fromhttp://toxicolo gy.ucsd.edu/art $\% 202 \% 20$ methemoglobin.pdf

[25] https://blogs.scientificamerican.com/tetrapod-zoology/africanmole-rats-so-much-more-than-just-the-naked-mole-rat/

[26] http://www.funscience.in/study-zone/Biology/Respiration/Res pirationInPlants.php 